\title{
Contribution of C3G and other GEFs to liver cancer development and progression
}

\author{
Almudena Porras $^{1,2}$, Celia Sequera ${ }^{1,2,3}$, Paloma Bragado ${ }^{1,2}$, Alvaro Gutierrez-Uzquiza ${ }^{1,2}$, Carmen Guerrero $^{4,5,6}$ \\ 'Departamento de Bioquímica y Biología Molecular, Facultad de Farmacia, Universidad Complutense de Madrid, Madrid 28040, \\ Spain. \\ ${ }^{2}$ Instituto de Investigación Sanitaria del Hospital Clínico San Carlos (IdISSC), Madrid 28040, Spain. \\ ${ }^{3}$ Aix-Marseille Univ, CNRS, Developmental Biology Institute of Marseille (IBDM), UMR7288, Parc Scientifique de Luminy, \\ Marseille 13009, France. \\ ${ }^{4}$ Instituto de Biología Molecular y Celular del Cáncer (IMBCC), Universidad de Salamanca-CSIC, Salamanca 37007, Spain. \\ ${ }^{5}$ Instituto de Investigación Biomédica de Salamanca (IBSAL), Salamanca 37007, Spain. \\ ${ }^{6}$ Departamento de Medicina, Universidad de Salamanca, Salamanca 37007, Spain.
}

Correspondence to: Prof. Almudena Porras, Departamento de Bioquímica y Biología Molecular, Facultad de Farmacia, Universidad Complutense de Madrid, Plaza Ramón y Cajal s/n, Madrid 28040, Spain. E-mail: maporras@ucm.es

How to cite this article: Porras A, Sequera C, Bragado P, Gutierrez-Uzquiza A, Guerrero C. Contribution of C3G and other GEFs to liver cancer development and progression. Hepatoma Res 2021;7:40. https://dx.doi.org/10.20517/2394-5079.2021.16

Received: 22 Jan 2021 First Decision: 1 Apr 2021 Revised: 12 Apr 2021 Accepted: 16 Apr 2021 Published: 17 May 2021

Academic Editor: Isabel Fabregat Copy Editor: Yue-Yue Zhang Production Editor: Yue-Yue Zhang

\begin{abstract}
Primary liver cancers constitute the fourth leading cause of cancer mortality worldwide, due to their high morbidity, late diagnosis and lack of effective treatments. Hepatocellular carcinoma (HCC) represents $80 \%$ and cholangiocarcinoma (CCA) 15\% of liver cancers. Several genetic and epigenetic gene alterations (e.g., TERT, TP53 or CTNNB1) are HCC drivers, although many additional gene alterations contribute to HCC initiation and/or progression. Rho and Ras GTPases have been widely implicated in tumorigenesis and their activators (GEFs) have recently emerged as putative key players in liver cancer. The Ras GEF, C3G (RAPGEF1), a GEF mainly for Rap proteins, has recently been uncovered as a relevant gene in HCC. Its upregulation promotes tumor growth, although a decrease in C3G levels favors migration/invasion and lung metastasis. Rap1A/1B/2A/2B are overexpressed in HCC tumors, but their effects are controversial and not equivalent to those of C3G. The C3G partner, CRKL, is also overexpressed in HCC, promoting proliferation, migration and invasion. Various Rho GEFs are also deregulated in liver cancer. Tiam1 and Tiam2 expression is upregulated in HCC, promoting proliferation, migration and metastasis. In addition, ARHGEF-10L/9/19/39 are overexpressed in HCC tumors, facilitating migration, invasion, metastasis and proliferation. Another Rho GEF, Vav2, is also involved in metastasis. Little is known about the participation of these GEFs and GTPases in CCA. However, analysis of cancer databases uncovered deregulations or genetic alterations in several of these genes, in both CCA and HCC. Hence, GEFs
\end{abstract}


function appear essential for liver homeostasis, although future studies are needed to define their precise function in liver cancer.

Keywords: Liver cancer, C3G, RAPGEF1, Rap, Ras GEFs, Rho GEFs, CRK, hepatocarcinoma, cholangiocarcinoma

\section{INTRODUCTION}

Primary liver cancer is the 6th most frequently diagnosed cancer and the 4th leading cause of cancer mortality worldwide ${ }^{[1]}$. It is refractory to most treatments, so life expectancy of patients is very low, with a 5year median survival of $18 \%{ }^{[2]}$.

The most common type of primary liver cancer is hepatocellular carcinoma (HCC), followed by cholangiocarcinoma (CCA), a highly heterogeneous group of malignancies generated in the biliary tree, which represents approximately $15 \%$ of primary liver tumors ${ }^{[3]}$. Some classifications also include hepatoblastoma and combined HCC and $\mathrm{CCA}^{[4]}$. All these primary liver cancers can potentially originate by hepatocytes, cholangiocytes, hepatoblasts and/or liver progenitor cells. However, the cell of origin is still controversial ${ }^{[4]}$. The combined effects of oncogenic driver genes (intrinsic factors) and tumor microenvironment (extrinsic factors) determine the cancer phenotype of hepatocyte-derived liver tumors.

HCC usually occurs in the context of chronic liver disease, originated by risk factors such as infection with hepatitis B (HBV) or C viruses, alcohol abuse and nonalcoholic hepatic steatosis ${ }^{[2]}$. HCC has high molecular heterogeneity at different levels: interpatient, intertumoral (in different nodules) and intratumoral (in the same nodule).

The most frequent alterations in HCC include mutations in the TERT promoter leading to TERT reactivation; TP53 alterations; CTNNB1 mutations; copy number variations in CCDN1, MYC, MET and $E R B B 2$; and alterations in DNA methylation ${ }^{[2,5]}$. In addition, many more genes contribute to HCC progression, including Ras and other members of this superfamily of GTPases.

Proteins from Ras and Rho families belong to the Ras superfamily of GTPases and are closely related structurally. Based on their sequence homology and functionality, they are sorted into 5 families: Ras, Rho, Rab, Ran and Arf ${ }^{[6]}$. They act as molecular switches, cycling between inactive (GDP-bound state) and active (GTP-bound state) conformations. Guanine nucleotide Exchange Factors (GEFs) catalyze the release of GDP, favoring GTP binding. After the activation of effector pathways, GTP is rapidly hydrolyzed to GDP in a reaction accelerated by GAPs (GTPase activating proteins) ${ }^{[7]}$. Rho GTPases are also regulated by GDPdissociation inhibitors ${ }^{[6,8]}$. Although Ras proteins are more frequently mutated in human cancer ${ }^{[9]}$, mutations in Rho family of GTPases, mainly Rho and Rac, have also been described ${ }^{[10-12]}$. In fact, Rho GTPase deregulation may contribute not only to cancer cell proliferation but also to invasion and $\operatorname{metastasis}^{[13]}$.

In mammals, the Ras family comprises 36 members that regulate cell growth, differentiation and survival. Ras proteins are classified into 4 main subfamilies, namely Ras, Rap, Ral and R-Ras, each with several members ${ }^{[14]}$. They are activated by GEFs harboring a CDC25-homology domain that, together with the REM (Ras Exchange Motif) module, constitute the GEF-catalytic domain, which is conserved from yeast to humans ${ }^{[15]}$. Ras GEFs are classified into different protein families according to their specific, non-catalytic modules: C3G (RAPGEF1), PDZ-GEF1/2 (RAPGEF2/6), EPAC1/2 or CAMP-GEFI/II (RAPGEF3/4), MRGEF (RAPGEF5), SOS-1/2, Ras-GRF1/2, CalDAG-GEFII/I/III (RASGRP1/2/3), RasGRP4, RalGDS, RalGPS, 
DOCK4 and PLC-epsilon-1 (PLCE1) $)^{[15-17]}$.

Rho proteins (22 members in mammals) regulate actin cytoskeleton dynamics and vesicle trafficking ${ }^{[18]}$. They are activated by GEFs from either Dbl family (with 69 members), which contain a DH (Dblhomology) catalytic domain and a PH (plekstrin homology) domain ${ }^{[15,19]}$, or DOCK family (with 11 members), bearing a DHR2 (DOCK homology region 2) catalytic domain ${ }^{[20]}$.

Both Ras GEF and Rho GEF families channel different signaling pathways that lead to the activation of specific GTPases, providing a fine-tuned regulation. In addition, their multi-domain structure allows complex autoregulatory mechanisms for the modulation of their target GTPases, some of which are still unknown. In the case of $\mathrm{C}_{3} \mathrm{G}$, this mechanism has recently been uncovered ${ }^{[21]}$. Due to their function as specific GTPase activators, GEFs are susceptible nodes in the cell that modulate several signaling pathways such as MAPKs (ERKs, JNKs and p38 MAPKs) or PI3K. Consequently, their aberrant function is associated with a large number of human diseases, including cancer, where they may act as either promoters or suppressors of tumor growth and progression ${ }^{[22]}$.

Some Ras and Rho proteins and their GEFs play specific roles in the liver. The cAMP/EPAC/Rap1 cascade is an important pro-survival pathway for hepatocytes with an inhibitory role in gluconeogenesis. In addition, EPAC1 acting through Rap1 protects from fibrosis by suppressing the activation and proliferation of hepatic stellate cells, while EPAC2/Rap1 plays a profibrotic role ${ }^{[23]}$. The EPAC2/Rap1 pathway also regulates lipid metabolism in the liver ${ }^{[24]}$. Moreover, Rap promotes proliferation during liver regeneration ${ }^{[23]}$, and the Rho GEF, Ect2, also plays a role in liver regeneration ${ }^{[25]}$.

The Rac GEF, Vav1, through a non-canonical p38MAPK pathway, decreases hepatocyte cell death during acute liver inflammation ${ }^{[26]}$. Another Rac GEF, P-Rex2, controls glucose homeostasis in the liver and inhibits PTEN in a Rac GEF-independent manner ${ }^{[27]}$.

GEFs are deregulated in cancer through somatic mutations, changes in gene expression or post-translational modifications. Examples of Ras GEFs implicated in human cancer are RasGRF2, CalDAG-GEFI, CalDAGGEFII, RasGRP4 and Sos-1 (Ras subfamily); C3G, DOCK4 and PLC- -1 (Rap subfamily); and RalGDS, Rgl1/2 and Rgr (Ral subfamily). Among Rho GEFs, aberrant activity of Mcf-2, Vav1-3, Bcr, ECT2, ARHGEF2/4/5/7/11/12/17, Trio, OBSCN, SPATA13, P-Rex1, P-Rex2a, Net1, AKAP13, Lfc, Tiam1, Ost, Clg (Dbl family) and DOCK1, 2/3/8/10 (DOCK family) has also been found in tumors ${ }^{[22,28-30]}$.

Particularly, the deregulation of some of Ras and Rho GEFs has been associated with HCC progression and metastasis, justifying the growing interest. Here, we summarize the most remarkable data on this subject.

\section{C3G AND OTHER RAS GEFS IN LIVER CANCER}

C3G (Crk SH3-domain-binding guanine-nucleotide-releasing factor) is a GEF for Rap1 and other Ras proteins, such as R-Ras ${ }^{[31,32]}$. However, several C3G functions are not dependent on its GEF activity, but rather rely on its interaction with other proteins through its proline-rich domain and/or its ability to translocate to the nucleus ${ }^{[33-36]}$. There are two main $\mathrm{C} 3 \mathrm{G}$ isoforms, $\mathrm{A}$ (the most common) and $\mathrm{B}$, with 21 amino acids replacing 3 from the $\mathrm{N}$-terminal domain ${ }^{[37]}$. C3G is essential for embryonic development ${ }^{[38]}$ and regulates several cellular functions such as adhesion, migration, apoptosis and differentiation ${ }^{[37,39]}$ [Figure 1]. Its role in cancer depends on cellular context, tumor type and stage. C3G prevents malignant transformation induced by oncogenes in mouse fibroblast ${ }^{[3,40]}$ and its expression decreases in cervical squamous cell carcinoma ${ }^{[41]}$. In colon carcinoma (CRC), C3G plays a dual role, inhibiting migration and 


\section{CELLULAR FUNCTIONS}

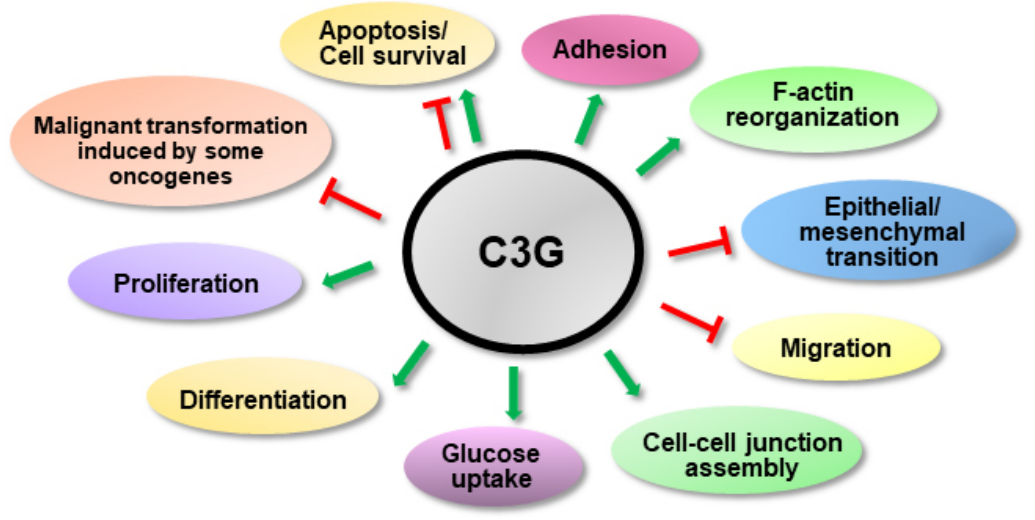

Figure 1. C3G cellular functions. The scheme shows the positive (green) or negative (red) regulation of different cellular functions by C3G.

invasion, while favoring tumor growth ${ }^{[42]}$. C3 $\mathrm{G}$ also reduces migration in highly invasive breast cancer cells $^{[43]}$. In non-small-cell lung cancer, C3G levels increased ${ }^{[44]}$, suggesting a role as a tumor promoter. In this line, $\mathrm{p} 87 \mathrm{C} 3 \mathrm{G}$ isoform (lacking the most $\mathrm{N}$-terminal region) is upregulated in chronic myeloid leukemia (CML) and associated with this disease ${ }^{[45]}$.

Until very recently, there was no information in the literature supporting a role for $\mathrm{C} 3 \mathrm{G}$ in liver cancer. The first data were obtained from different human cancer databases and indicate that RAPGEF1 mRNA levels increase in samples from HCC patients and in patient-derived xenografts, as compared to non-pathological liver samples ${ }^{[23]}$. Later, new analyses of cancer databases revealed that RAPGEF1 mRNA levels gradually increase in HCC patients as the disease progresses (from stages I to III), being also higher in HCC cell lines as compared to adult hepatocytes ${ }^{[46]}$ [Table 1]. This increase in $\mathrm{C} 3 \mathrm{G}$ levels is associated with a lower survival ${ }^{[46]}$, as is the presence of somatic mutations and other genetic alterations in RAPGEF1 gene (amplification, deletion, etc. $)^{[23]}$. C3G protein levels also increase in HCC cells, as compared to adult hepatocytes, and its downregulation by gene silencing reduces their tumorigenic properties, both in vitro and in vivo ${ }^{[46]}$. However, the reduction in $\mathrm{C}_{3} \mathrm{G}$ levels enhances the pro-migratory and pro-invasive capacity of HCC cells by favoring the acquisition of a more mesenchymal phenotype. Hence, low levels of C3G correlate with lung metastasis, although its growth is associated to the recovery of a high $C 3 G$ expression. Moreover, C3G is required for the correct activation of HGF/MET signaling in HCC cells ${ }^{[46]}$. All these data indicate that $\mathrm{C} 3 \mathrm{G}$ plays a key role in $\mathrm{HCC}$, promoting tumor growth, and the regulation of its levels may facilitate HCC growth and progression. However, the potential contribution of the main C3G target, Rap, to these actions of $\mathrm{C} 3 \mathrm{G}$ remains unclear.

Little is known about Rap function in HCC and the available data are controversial. Transfection of Rap1 decreases proliferation of Hep3B cells by reducing ERKs activation and suppresses tumor growth ${ }^{[47]}$. In contrast, Rap1B is upregulated in HBV-induced HCC, promoting proliferation and migration ${ }^{[4]}$. More recent studies also revealed an upregulation of either $R A P_{2} B^{[49]}$ or $R A P 1 B$ expression $^{[50]}$ in human HCC samples and in some cell lines, which leads to an increased proliferation, tumor growth and migration. In addition, our analyses of data from HCC patient samples obtained from TCGA database also show no changes in $R A P 2 C$, but an increase in $R A P_{1} A / 1 B / 2 A / 2 B$ mRNA levels that reaches statistical significance in the case of $R A P 2 A$, as compared to non-pathological samples [Figure 2]. This is associated with a significant 
Table 1. Ras and Rho GEFs involved in primary liver cancer

\begin{tabular}{|c|c|c|c|}
\hline Gene & Family & Effect & Ref. \\
\hline \multicolumn{4}{|l|}{ Ras GEFs } \\
\hline RAPGEF1 (C3G) & Ras (Rap) & $\begin{array}{l}\text { Upregulation (potential prognosis marker). } \\
\text { Regulates tumor growth and inhibits migration and invasion }\end{array}$ & {$[46]$} \\
\hline RAPGEF3 (EPAC1) & Ras (Rap) & Regulates liver fibrosis & {$[51]$} \\
\hline RASGRP1 & Ras (Ras) & Its upregulation promotes proliferation & {$[52]$} \\
\hline RASGRP3 & Ras (Ras) & Upregulation (potential prognosis marker) & {$[53]$} \\
\hline PLCE1 & Ras (Ras) & Upregulation (potential prognosis marker) & [53] \\
\hline \multicolumn{4}{|l|}{ Rho GEFs } \\
\hline TIAM1 & Rho (Dbl) & Upregulation and/or increased activity & {$[70,72-82]$} \\
\hline TIAM2 & Rho (Dbl) & Upregulation and/or increased activity & {$[83,84]$} \\
\hline VAV2 & Rho (Dbl) & Its downregulation decreases metastatic abilities & {$[98]$} \\
\hline VAV3/KLF6 & Rho (Dbl) & Increased activity & {$[97]$} \\
\hline ARHGEF2 (GEFH1) & Rho (Dbl) & Its downregulation decreases metastatic abilities & [103] \\
\hline \multirow[t]{2}{*}{ ECT2 } & Rho (Dbl) & Upregulation & [91] \\
\hline & & Its downregulation decreases metastatic abilities & [92-94] \\
\hline AKAP13 (LBC) & Rho (Dbl) & Upregulation (potential prognosis marker) & {$[95]$} \\
\hline ARHGEF39 & Rho (Dbl) & Upregulation (potential prognosis marker) & {$[87,88]$} \\
\hline FGD1 & Rho (Dbl) & Upregulation & [99] \\
\hline ARHGEF19 & Rho (Dbl) & Its activity promotes metastasis & [89] \\
\hline TRIO & Rho (Dbl) & Upregulation & [104] \\
\hline NET1 & Rho (Dbl) & Upregulation (potential prognosis marker) & [101] \\
\hline ARHGEF1OL & Rho (Dbl) & Upregulation (potential prognosis markers) & {$[85]$} \\
\hline
\end{tabular}

Ras and Rho GEFs with a deregulated expression in liver cancer (HCC and/or CCA) are included. It is indicated for each one whether its expression is upregulated or downregulated, its effect, its potential value as a prognostic biomarker and the reference(s). HCC: Hepatocellular carcinoma; CCA: cholangiocarcinoma.

reduction in the overall survival, while no differences in disease-free survival are observed. RAP1A/1B/2A/ $2 B / 2 C$ genes also present amplifications or other genetic alterations in HCC [Figure 3].

The effects of $\mathrm{C} 3 \mathrm{G}$ and Rap proteins are not equivalent, suggesting that $\mathrm{C} 3 \mathrm{G}$ might have Rap-dependent and -independent actions in HCC. Other Rap GEFs such as EPAC1/2 could contribute to regulate Rap activity. Although there are no data about them, EPAC1/2 regulate liver fibrosis ${ }^{[51]}$ [Table 1], a previous step towards HCC development.

Concerning the potential role of other Ras GEFs in HCC, RASGRP1 is upregulated in HCC patient samples and human HCC cell lines, promoting proliferation ${ }^{[52]}$. RASGRP3 and PLCE1 are also upregulated ${ }^{[53]}$. Other Ras GEFs, such as RALGPS2 or RGL1, could play a role, based on genetic alterations found in TCGA [Figure 3].

In CCA, the function of $\mathrm{C} 3 \mathrm{G}$ and/or Rap remains unknown. Using data from a TCGA cohort of patients with CCA, we found a significant increase in the mRNA levels of C3G (RAPGEF1), RAP1A/1B and RAP2A/ $2 B$, but not of $R A P_{2} C$, in tumors as compared to non-pathological liver samples [Figure 4] and genetic alterations [Figure 3]. Surprisingly, in contrast to HCC data, the increased levels of RapGEF1 and Rap family members are not associated with a lower overall survival. These results reinforce the idea that, although hepatocytes and cholangiocytes share a common liver bipotential progenitor, HCC and CCA are clinically two distinct entities in terms of mechanisms, diagnosis and treatment ${ }^{[54]}$. Hence, more studies are 


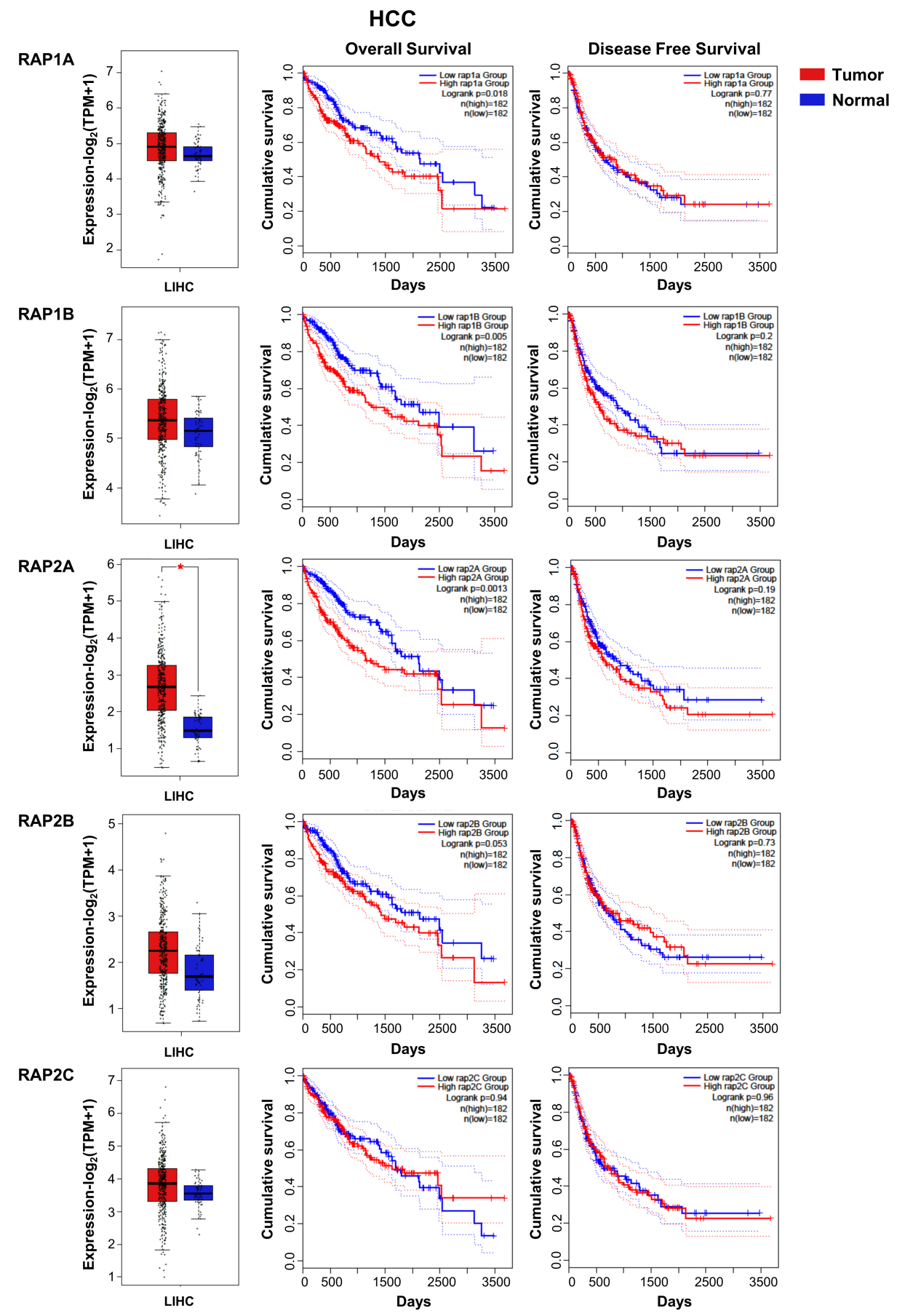

Figure 2. RAP GTPases mRNA expression in $\mathrm{HCC}$ patients and its relationship with survival. From top to bottom, RAP1A, $-1 B,-2 A,-2 B$ and -2C: Box plots (left) show mRNA levels expressed as log2 (TPM + 1) in tumor (red) and adjacent liver non-pathological (blue) samples. Kaplan-Meier curves show overall survival (middle) and disease-free cumulative survival (right), comparing patients with high (red) vs. low (blue) expression levels for each analyzed gene (median TPM cutoff was chosen). All data were generated through GEPIA2 portal (Gene Expression Profiling Interactive Analysis; http://gepia2.cancer-pku.cn/\#index). Log rank value is indicated for each curve. GEPIA2 mRNASeq dataset analyses are based on UCSC Xena project (http://xena.ucsc.edu) TCGA-LIHC [Liver Hepatocellular Carcinoma (HCC)] cohort for (50 normal and 371 tumor samples) patients. Results are considered statistically significant for $P$ values $\leq 0.05\left(^{*}\right)$

necessary to uncover the specific characteristics of CCAs. Additionally, the limited number of CCA samples 


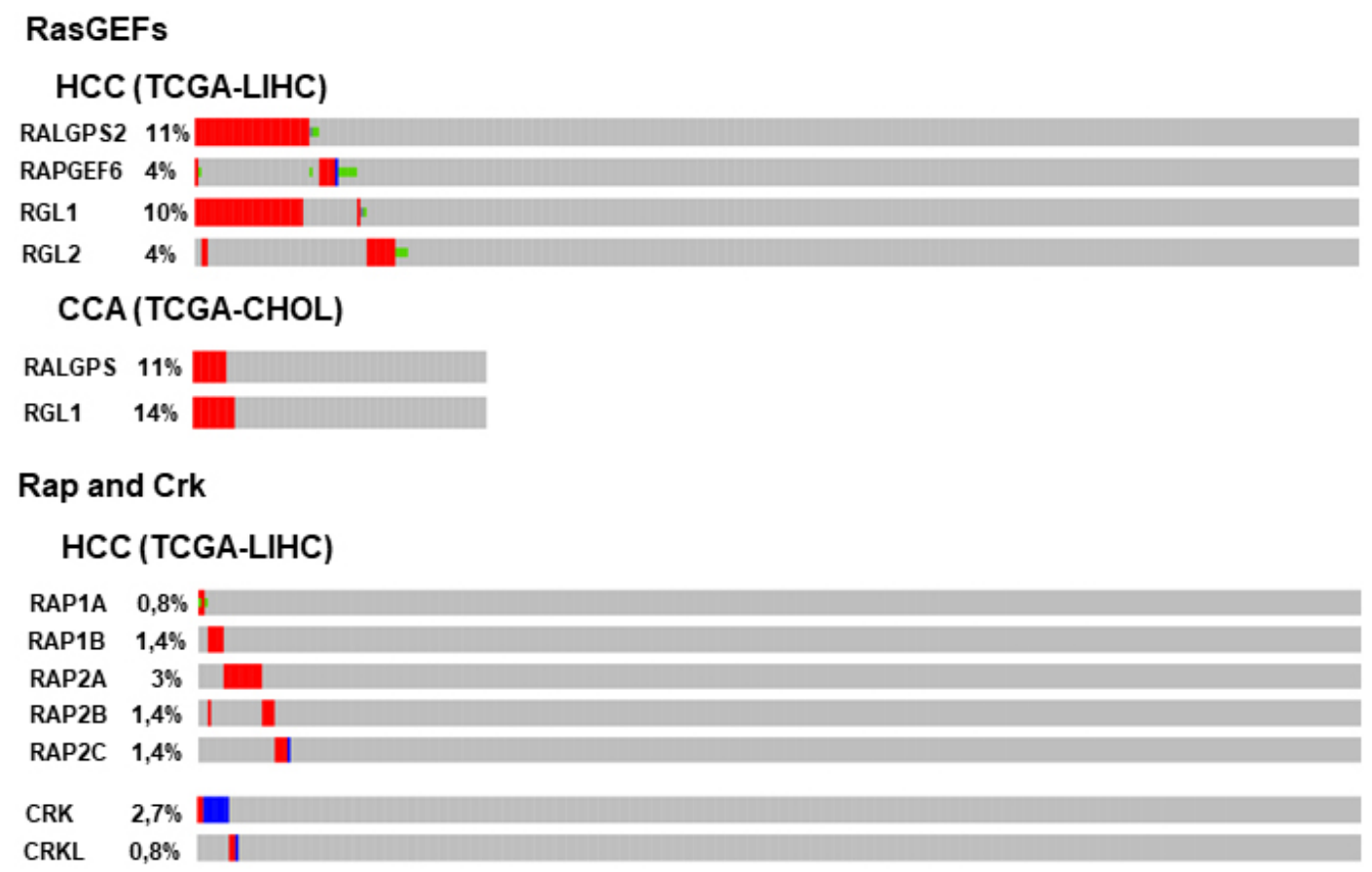

\section{CCA (TCGA-CHOL)}

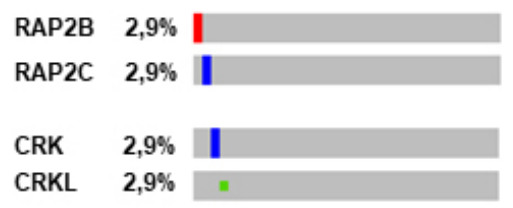

\section{Genetic Alterations}

Amplification
| Deep Deletion
Missense Mutation
Truncating Mutation
Splice Mutation
Inframe Mutation

Figure 3. Frequent genetic alterations in Ras GEFs, Rap and CRK genes in HCC and CCA. The percentage of patients (for Ras GEFs only when $\geq 4 \%$ ) with genetic alterations for genes from Ras GEFs, Rap and CRK family are shown. The type of these alterations is indicated by the color, as specified in the legend. Mutation data from whole exome sequencing were taken from cBioportal (https://www.cbioportal.org/) from Liver Hepatocellular Carcinoma [TCGA (TCGA-LIHC), Firehose Legacy, 442 samples] and Cholangiocarcinoma [TCGA (TCGA-CHOL), Firehose Legacy, 51 samples]. HCC: Hepatocellular carcinoma; CCA: cholangiocarcinoma.

available in the TCGA-CHOL dataset can bias result interpretation.

Regarding the potential regulation of $\mathrm{C} 3 \mathrm{G}$ expression by miRNAs, it is important to mention that, although bioinformatic tools, such as TargetScanHuman database (www.targetscan.org), predict potential interactions of different miRNAs with RAPGEF1 gene, there are no publications validating in vitro or in vivo the existence of these interactions in any model. However, miR-27a, which reduces viral replication and infectivity of HBV in human hepatoma cells, can repress RAPGEF2 in Huh7.5 HCC cells ${ }^{[55]}$.

On the other hand, considering that the aberrant activation of the Ras pathway is a common feature in HCC, downregulation of Ras GAPs such as RASAL1, DAB2IP or NF1 was found in HCC samples, in the absence of Ras mutations, being associated with reduced patient survival ${ }^{[5]}$. 


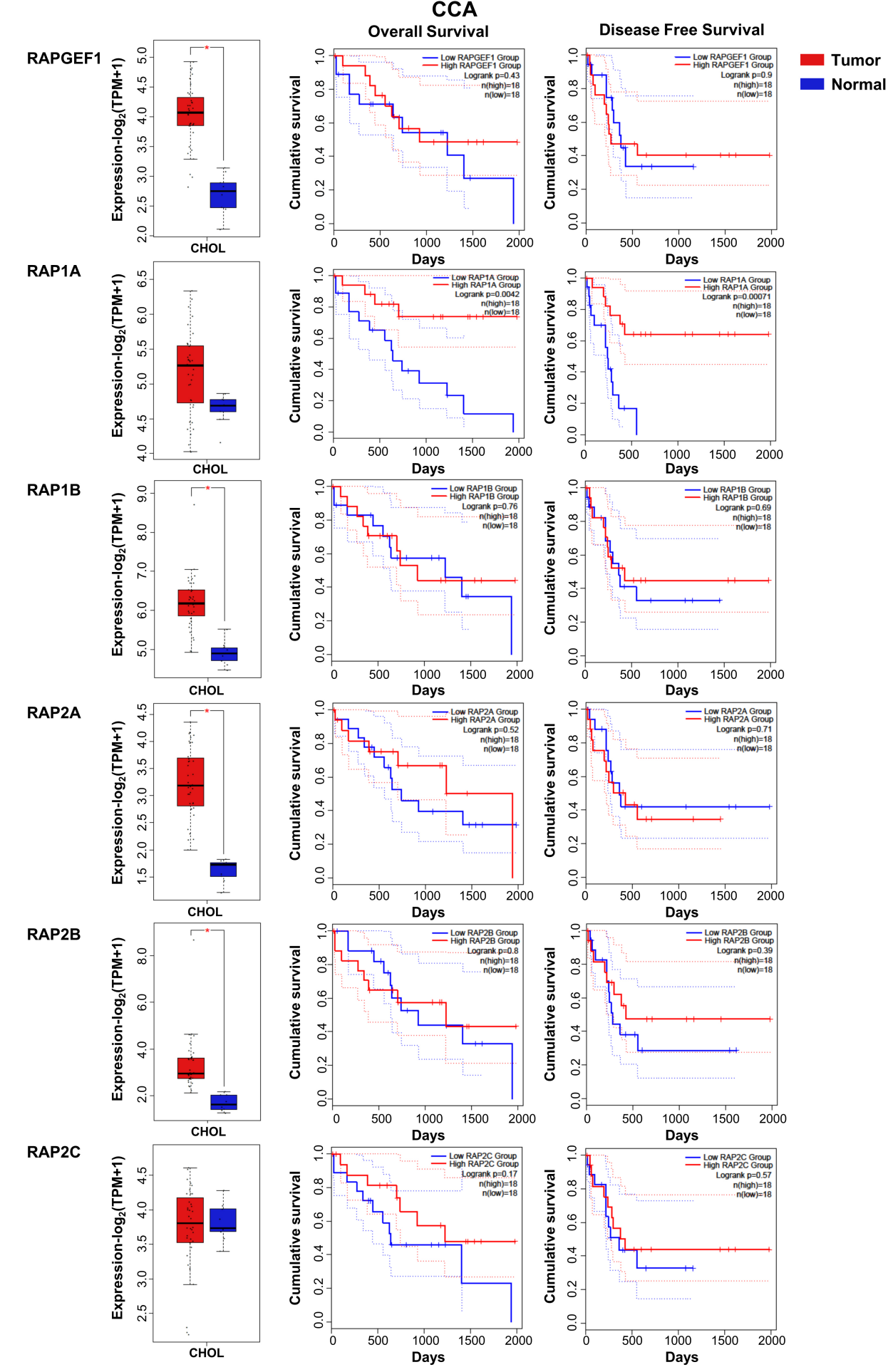

Figure 4. RAPGEF1 and RAP GTPases mRNA expression in CCA patients and its relationship with survival. From top to bottom, RAPGEF1, RAP1A, $-1 B,-2 A,-2 B$ and -2C: Box plots (left) show mRNA levels expressed as log2 (TPM + 1) in tumor (red) and adjacent liver nonpathological samples (blue) samples. Kaplan-Meier curves show overall survival (middle) and disease-free cumulative survival (right), comparing patients with high (red) vs. low (blue) expression levels of each analyzed gene (median TPM cutoff was chosen). All data were generated through GEPIA2 portal (Gene Expression Profiling Interactive Analysis; http://gepia2.cancer-pku.cn/\#index). Log rank value is indicated for each curve. GEPIA2 mRNASeq dataset analyses are based on UCSC Xena project (http://xena.ucsc.edu) TCGA$\mathrm{CHOL}$ (9 normal and 36 tumor samples) from patients. Results are considered statistically significant for $P$ values $\leq 0.05\left(^{\star}\right)$. CCA: Cholangiocarcinoma. 


\section{CRK, A C3G BINDING PROTEIN WITH A ROLE IN HCC}

CRK (CT10 regulation of Kinase) proteins are adaptors involved in the activation of several signaling pathways ${ }^{[5]}$. This family of proteins encompasses two alternative spliced isoforms, CRKI and CRKII, and the related CRKL [v-crk sarcoma virus CT10 oncogene homolog (avian)-like] protein. They are ubiquitously expressed and conserved throughout eukaryotes. CRK proteins harbor one N-terminal Src homology 2 (SH2) domain and one (in CRKI) or two (in CRKII and CRKL) C-terminal Src homology 3 $(\mathrm{SH} 3)$ domain $^{[58]}$, which are essential to interact with a great number of signaling molecules such as Sos, Gab1, Bcr-Abl, p130Cas and C3G. This allows the integration of a great variety of signals, leading to the regulation of several cellular functions. In cancer, CRK proteins play important roles. CRKL is overexpressed in a number of cancers such as gastric cancer, glioblastoma, lung cancer, CML and HCC ${ }^{[59]}$. Moreover, in breast cancer patients, high soluble CRKL levels are found in the serum, associated with advanced stages of the disease ${ }^{[60]}$.

CRKL has been proposed as a prognostic biomarker for HCC based on its high expression in patient samples and its inverse correlation with the overall survival of HCC patients ${ }^{[61]}$. In addition, CRKL promotes migration in HCC cells. Several studies have demonstrated that CRKL is overexpressed in HCC, inducing migration, invasion and proliferation ${ }^{[62-64]}$. In agreement with this, our analysis using TCGA data revealed an increase in CRKL mRNA levels in HCC patient samples as compared to control liver [Figure 5]. Moreover, high $C R K L$ levels are associated to a lower survival. In CCA, CRK and CRKL expression is increased, being statistically significant for CRKL [Figure 5].

Some of the mechanisms responsible for CRKL regulation have been uncovered. It is noticeable that $C R K L$ expression is tightly regulated by different miRNAs in the liver and this regulation is altered in HCC. Hence, p53-induced miRNA-215 downregulates CRKL, acting through the long non-coding RNA PCAT-1, which decreases proliferation, tumor growth and migration/invasion of hepatocyte ${ }^{[63]}$. However, in HCC cells, this mechanism fails. Similarly, miR-429 negatively regulates CRKL expression post-transcriptionally, a mechanism altered in HCC, leading to an increased migration and invasion mediated by CRKL upregulation ${ }^{[62]}$. ERKs activation and epithelial-mesenchymal transition (EMT) contribute to these actions of the miR-429-CRKL axis. Furthermore, the upregulation in HCC of the transcription factor E-Twenty-Six variant gene 6, a negative regulator of miR-429 expression, leads to CRKL overexpression and enhances migration and invasion ${ }^{[64]}$. Additionally, CRKL downregulates $m i R-429$ expression. On the other hand, the long non-coding RNA AFAP1-AS1 (Actin filament-associated protein 1 antisense RNA 1), upregulated in HCC, also induces HCC proliferation, migration and invasion through increasing CRKL levels, leading to a higher AFAP1-AS1 expression ${ }^{[65]}$. In contrast to all this, a previous work showed that CRKL overexpression decreased in vitro proliferation, migration and invasion in the murine hepatocarcinoma Hca-P cell line ${ }^{[6]}$.

Another member of the CRK family, CRKII, could also contribute to promote HCC progression based on the increased proliferation, migration and invasion induced by CRKII overexpression in Hca-P cells ${ }^{[67]}$. In agreement with this, the induced upregulation of CRKI/II and Rac1 by Annexin 5 in HCC mediates proliferation and invasion of Hca-P cells and xenograft tumor growth ${ }^{[68]}$.

In CCA, data from TCGA indicate the existence of deep deletions in CRK and missense mutations in CRKL [Figure 3].

In conclusion, although $\mathrm{CRK}$ is a $\mathrm{C} 3 \mathrm{G}$ partner, its role in $\mathrm{HCC}$ is not necessarily associated with $\mathrm{C} 3 \mathrm{G}$, but it may depend on complex interactions with different proteins. 

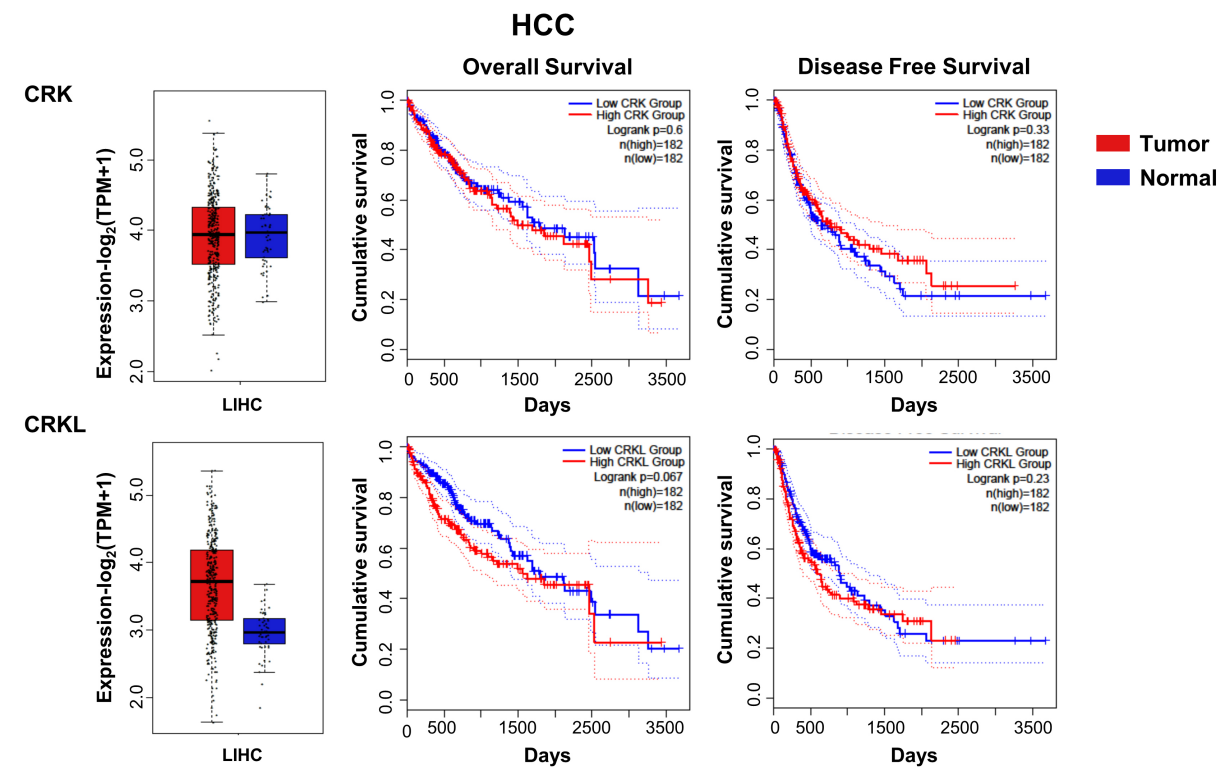

CCA
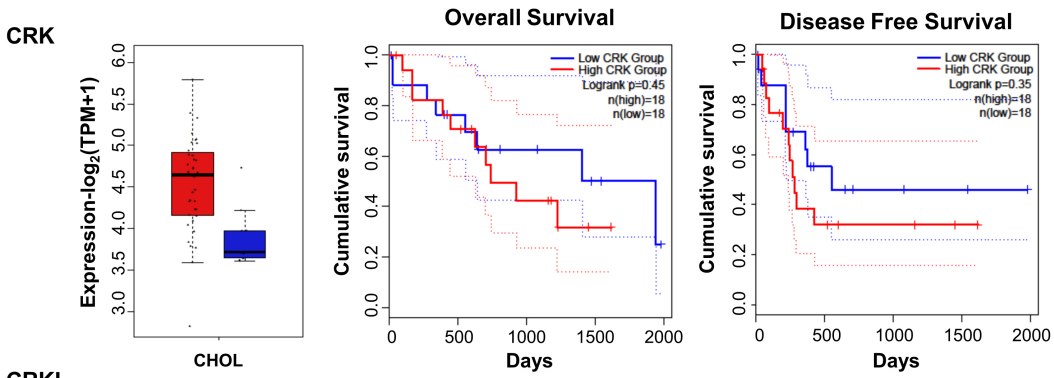

CRKL
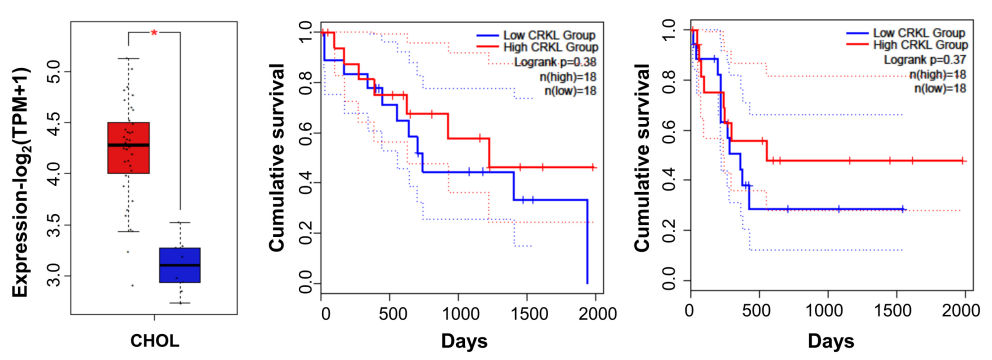

Figure 5. CRK and CRKL mRNA expression in HCC and CCA patients and its relationship with survival. Box plots (left) show CRK and CRKL mRNA levels expressed as log2 (TPM + 1) in tumor (red) and adjacent liver non-pathological samples (blue) samples. KaplanMeier curves show overall survival (middle) and disease-free survival probability (right) comparing patients with high (red) vs. low (blue) expression levels of each analyzed gene (median TPM cutoff was chosen). All data were generated through GEPIA2 portal (Gene Expression Profiling Interactive Analysis; http://gepia2.cancer-pku.cn/\#index). Log rank value is indicated for each curve. GEPIA2 mRNASeq dataset analyses are based on UCSC Xena project (http://xena.ucsc.edu) TCGA-LIHC and TCGA-CHOL, for HCC (50 normal and 371 tumor samples) and CCA ( 9 normal and 36 tumor samples) patients, respectively. Results are considered statistically significant for $P$ values $\leq 0.05\left(^{\star}\right)$. HCC: Hepatocellular carcinoma; CCA: cholangiocarcinoma.

\section{RHO GEFS IN LIVER CANCER}

As mentioned above, alterations of Rho and Ras GEFs have been frequently reported in liver cancer, being protein levels upregulation or hyperactivity the most reported events. In addition, we found several genetic alterations in our analyses of databases in both HCC and CCA [Figure 6]. We summarize here the most significant Rho GEFs involved in liver cancer [Table 1]. 


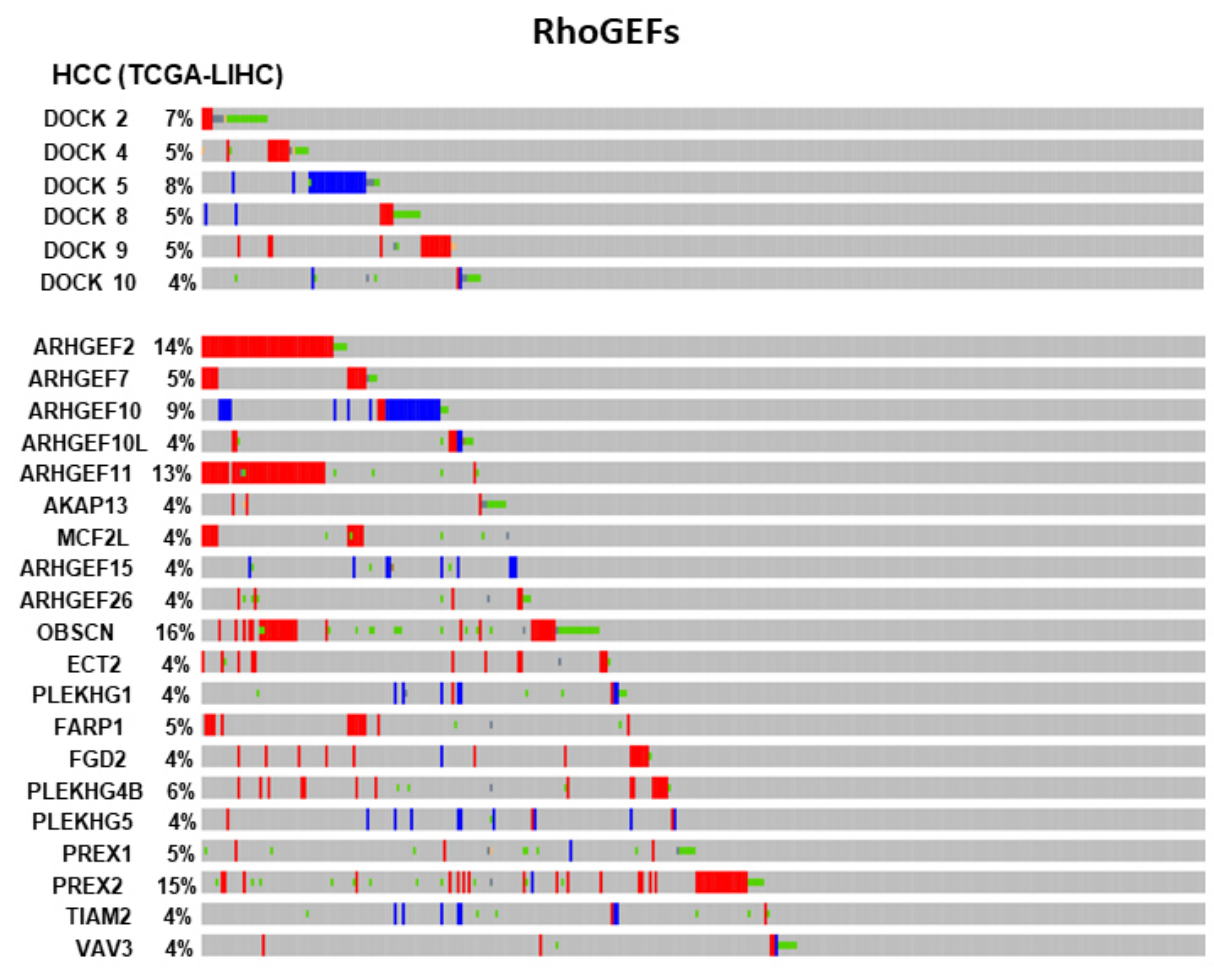

\section{CCA (TCGA-CHOL)}

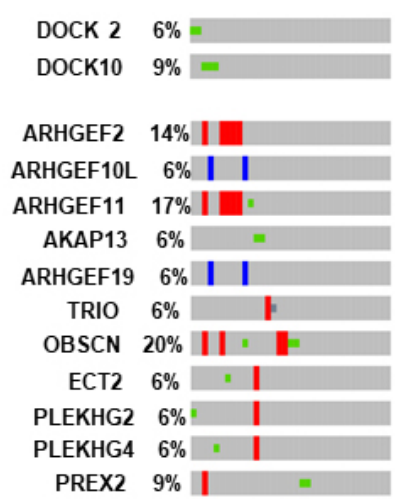

\section{Genetic Alterations}

Amplification No alterations
Deep Deletion

Missense Mutation

Iruncating Mutation

Splice Mutation

Inframe Mutation

Figure 6. Frequent genetic alterations in Rho GEFs genes in HCC and CCA. The percentage of patients (when $\geq 4 \%$ ) with genetic alterations for genes from Rho GEF family are shown. The type of these alterations is indicated by the color, as specified in the legend. Mutation data from whole exome sequencing were taken from cBioportal (https://www.cbioportal.org/) from Liver Hepatocellular Carcinoma (TCGA, Firehose Legacy, 442 samples) and Cholangiocarcinoma (TCGA, Firehose Legacy, 51 samples). HCC: Hepatocellular carcinoma; CCA: cholangiocarcinoma.

Tiam1 (T-cell lymphoma invasion and metastasis 1) protein is a Rac GEF that belongs to Dbl protein family ${ }^{[69]}$. It was identified as an invasion- and metastasis-promoting gene in a murine T-lymphoma cell line $\mathrm{e}^{[70]}$. Tiam 1 activates Rac1, inducing migration, invasion and metastasis of many tumor cells ${ }^{[7,72]}$. Furthermore, Tiam 1 has a significant role in promoting tumor progression in a variety of cancers, such as breast cancer, CRC and lung cancer ${ }^{[13,73,74]}$. Tiam 1 is much more strongly expressed in almost all HCCs than in normal liver and cirrhotic liver tissues ${ }^{[75]}$. Furthermore, Tiam1 and Rac1 expression is upregulated in HCC, which correlated with advanced clinical stages ${ }^{[75-77]}$ and a significant reduction in disease-specific survival ${ }^{[75]}$. However, the precise molecular mechanisms of Tiam1 actions in HCC tumorigenesis are still unknown. Overexpression of Tiam1 increases proliferation, migration and invasion in HCC cell lines ${ }^{[77]}$. 
Moreover, in vivo functional studies showed that Tiam 1 upregulation enhances tumorigenicity and metastatic potential, while Tiam 1 knockdown delays tumor growth and inhibits metastases formation ${ }^{[77]}$. A recent report also showed that Tiam 1 expression can be epigenetically regulated in HCC by KDM6B demethylase leading to invasion and metastasis ${ }^{[8,79]}$. MicroRNAs also regulate HCC migration and proliferation by modulating Tiam 1 expression ${ }^{[80,81]}$. Interestingly, Tiam 1 expression is also increased in CCA, correlating with a higher degree of malignancy ${ }^{[82]}$. Furthermore, Tiam1 inhibition prevented CCA cell proliferation and migration ${ }^{[82]}$.

TIAM2 gene is a homolog of TIAM1, a Rac GEF with important roles in neuron development and human malignancies ${ }^{[60]}$. Tiam2 short form $($ TIAM2S $)$ is upregulated at both protein and mRNA levels in HCC $^{[83]}$. Posttranscriptional regulation, mainly achieved by SP1 transcription factor, induces TIAM2S mRNA expression in HCC cell lines ${ }^{[84]}$. TIAM2S promotes cell growth and invasion through EMT regulation, being associated with a metastatic phenotype of $\mathrm{HCCs}^{[83]}$.

ARHGEF10L (Rho guanine nucleotide exchange factor 10-Like) is a specific GEF for RhoA. ARHGEF10L is upregulated in HCC, especially at stage $\mathrm{III}^{[85]}$, promoting HCC proliferation and invasion through activation of the RhoA-ROCK1-ERM (ezrin/radixin/moeisin) pathway and EMT induction ${ }^{[85]}$.

ARHGEF39 (or C9orf100) is a member of the human Dbl family of Rho GEFs ${ }^{[86]}$. ARHGEF39 mRNA and protein levels are upregulated in HCC samples compared to non-pathological adjacent liver tissue ${ }^{[87,88]}$, and its expression correlates with worse prognosis ${ }^{[87]}$. ARHGEF39 promotes cell proliferation and migration in HCC cell lines ${ }^{[88]}$.

Another ARHGEF, ARHGEF19, promotes HCC cell proliferation and invasion ${ }^{[89]}$. Interestingly, the microRNA miR-503 inhibits HCC invasion and metastasis through inhibition of ARHGEF19 expression ${ }^{[89]}$.

ARHGEF9 is a Rho GEF able to activate the Rho GTPase Cdc42. CHD1L (Chromodomain helicase/ATPase DNA binding protein 1-like gene) induces ARHGEF9 transcription, leading to Cdc42 activation, which promotes filopodia formation and EMT induction, enhancing HCC invasion and metastasis generation ${ }^{[0]}$. Hence, overexpression of ARHGEF9 positively correlates with CHD1L upregulation and poor disease-free survival ${ }^{[90]}$.

ECT2 (Epithelial cell transforming sequence two protein) is significantly associated with early recurrent HCC disease and poor survival ${ }^{[91,92]}$. Its knockdown prevents the activation of Rho/ERKs signaling, enhances apoptosis and reduces migration and invasion of HCC cells ${ }^{[91]}$. Furthermore, the microRNA miR-490-5p reduces HCC metastasis and stemness through ECT2 inhibition ${ }^{[2,93]}$. In addition, in CCA cells, miR-194 promotes apoptosis and inhibits proliferation and migration through ECT2 downregulation and Rho signaling blockade ${ }^{[94]}$.

Lbc (Lymphoid blast crisis, or AKAP13) is a Rho $\mathrm{GEF}^{[69]}$, originally isolated as an oncogene with increased GEF activity ${ }^{[95]}$. Lbc is not expressed in adult liver under physiological conditions. However, it is upregulated in $\mathrm{HCC}^{[96]}$. Lbc increases $\mathrm{HCC}$ cell growth and induces $\mathrm{Bcl}-2$ expression and BAD phosphorylation, which is involved in the generation of HCC resistance to doxorubicin ${ }^{[96]}$.

VAV2/3 are GEFs for RhoA, RhoG and Rac1 that modulate their activity, which is important for HCC cell migration. VAV3 expression its downregulated in HCC by the transcription factor KLF6. Thus, KLF6 depletion increases Rac1 activity in a VAV3-dependent manner ${ }^{[97]}$. VAV2 promotes Rac1 and Cdc42 
activation, leading to lamellipodia formation, facilitating metastasis of HCC cells. Interestingly, miRNA-195 suppresses angiogenesis and metastasis of HCC by inhibiting the expression of VEGF, VAV2 and Cdc42 $2^{[98]}$.

Several other GEFs are upregulated in HCC and might play a role as potential diagnosis and prognosis biomarkers of this cancer. Among them, FGD1, GEF-H1 and NET1 from Rho-GEF family can be highlighted ${ }^{[53,99-104]}$.

In contrast to Rho GEFs, Rho GAPs, such as DLC1 (Deleted in Liver Cancer 1) and DLC2, act as tumor suppressors in HCC. DLC1 gene is inactivated in hepatocarcinogenesis ${ }^{[105]}$, suppressing cell proliferation and migration ${ }^{[106]}$. DLC2 expression is also downregulated in $\mathrm{HCC}^{[107,108]}$, which is associated with cell differentiation and poor prognosis ${ }^{[108]}$.

\section{CONCLUSION}

GEFs are frequently deregulated and appear to be essential mediators in liver cancer. They may represent diagnosis biomarkers and attractive targets for liver cancer therapy. However, future studies are needed to establish their precise role in liver cancer. This would allow determining the potential relevance of targeting GEFs in HCC treatment, probably through the design of inhibitors for specific domains, as some of these proteins can act through GEF dependent and independent mechanisms.

\section{DECLARATIONS}

\section{Authors' contributions}

All the authors contribute to the writing of this review.

Performed the analysis of patient data from TCGA database: Sequera C

Coordinated all the work: Porras A

\section{Availability of data and materials}

Not applicable.

\section{Financial support and sponsorship}

The work was supported by grants from the Spanish Ministry of Economy and Competitiveness (SAF201676588-C2-1-R and PID2019-104143RB-C22 to Porras A; and SAF2016-76588-C2-2-R and PID2019104143RB-C21 to Guerrero G and PID2019-104991RB-Ioo to Bragado P), and by two grants from the Council of Education of Junta de Castilla y León, Spain (SA017U16 and SA078P20 to Guerrero C). All funding was cosponsored by the European FEDER Program. Sequera C was supported by a fellowship from Complutense University from Madrid. Gutierrez-Uzquiza A is supported by Madrid Community Program for Talent Attraction (MRF 2017-T1/BMD-5468). Bragado P received support from BBVA (Becas Leonardo 2018, BBM-TRA-0041).

\section{Conflicts of interest}

All authors declared that there are no conflicts of interest.

\section{Ethical approval and consent to participate}

Not applicable.

\section{Consent for publication}

Not applicable. 


\section{Copyright}

(C) The Author(s) 2021.

\section{REFERENCES}

1. Bray F, Ferlay J, Soerjomataram I, Siegel RL, Torre LA, Jemal A. Global cancer statistics 2018: GLOBOCAN estimates of incidence and mortality worldwide for 36 cancers in 185 countries. CA Cancer J Clin 2018;68:394-424. DOI PubMed

2. Craig AJ, von Felden J, Garcia-Lezana T, Sarcognato S, Villanueva A. Tumour evolution in hepatocellular carcinoma. Nat Rev Gastroenterol Hepatol 2020;17:139-52. DOI PubMed

3. Banales JM, Marin JJG, Lamarca A, et al. Cholangiocarcinoma 2020: the next horizon in mechanisms and management. Nat Rev Gastroenterol Hepatol 2020;17:557-88. DOI PubMed PMC

4. Wang G, Wang Q, Liang N, et al. Oncogenic driver genes and tumor microenvironment determine the type of liver cancer. Cell Death \& Disease 2020;11:313. DOI PubMed PMC

5. Arechederra M, Daian F, Yim A, et al. Hypermethylation of gene body $\mathrm{CpG}$ islands predicts high dosage of functional oncogenes in liver cancer. Nat Commun 2018;9:3164. DOI PubMed PMC

6. Colicelli J. Human RAS superfamily proteins and related GTPases. Sci STKE 2004;2004:RE13. DOI PubMed PMC

7. Vetter IR, Wittinghofer A. The guanine nucleotide-binding switch in three dimensions. Science 2001;294:1299-304. DOI PubMed

8. Cherfils J, Zeghouf M. Regulation of small GTPases by GEFs, GAPs, and GDIs. Physiol Rev 2013;93:269-309. DOI PubMed

9. Li S, Balmain A, Counter CM. A model for RAS mutation patterns in cancers: finding the sweet spot. Nat Rev Cancer 2018;18:76777. DOI PubMed

10. Kazanietz MG, Caloca MJ. The Rac GTPase in Cancer: From Old Concepts to New Paradigms. Cancer Res 2017;77:5445-51. DOI PubMed PMC

11. Casado-Medrano V, Baker MJ, Lopez-Haber C, et al. The role of Rac in tumor susceptibility and disease progression: from biochemistry to the clinic. Biochem Soc Trans 2018;46:1003-12. DOI PubMed PMC

12. Bustelo XR. RHO GTPases in cancer: known facts, open questions, and therapeutic challenges. Biochem Soc Trans 2018;46:741-60. DOI PubMed

13. Sahai E, Marshall CJ. RHO-GTPases and cancer. Nat Rev Cancer 2002;2:133-42. DOI PubMed

14. Reuther GW, Der CJ. The Ras branch of small GTPases: Ras family members don't fall far from the tree. Curr Opin Cell Biol 2000;12:157-65. DOI PubMed

15. Bos JL, Rehmann H, Wittinghofer A. GEFs and GAPs: critical elements in the control of small G proteins. Cell 2007;129:865-77. DOI PubMed

16. Rebhun JF, Chen H, Quilliam LA. Identification and characterization of a new family of guanine nucleotide exchange factors for the ras-related GTPase Ral. J Biol Chem 2000;275:13406-10. DOI PubMed

17. Ferro E, Trabalzini L. RalGDS family members couple Ras to Ral signalling and that's not all. Cell Signal 2010;22:1804-10. DOI PubMed

18. Ridley AJ. Rho GTPases and actin dynamics in membrane protrusions and vesicle trafficking. Trends Cell Biol 2006;16:522-5229. DOI PubMed

19. Rossman KL, Der CJ, Sondek J. GEF means go: turning on RHO GTPases with guanine nucleotide-exchange factors. Nat Rev Mol Cell Biol 2005;6:167-80. DOI PubMed

20. Cote JF, Vuori K. GEF what? Trends Cell Biol 2007;17:383-93. DOI PubMed PMC

21. Carabias A, Gomez-Hernandez M, de Cima S, et al. Mechanisms of autoregulation of C3G, activator of the GTPase Rap1, and its catalytic deregulation in lymphomas. Sci Signal 2020;13:eabb7075. DOI PubMed

22. Vigil D, Cherfils J, Rossman KL, Der CJ. Ras superfamily GEFs and GAPs: validated and tractable targets for cancer therapy? Nat Rev Cancer 2010;10:842-57. DOI PubMed PMC

23. Sequera C, Manzano S, Guerrero C, Porras A. How Rap and its GEFs control liver physiology and cancer development. C3G alterations in human hepatocarcinoma. Hepat Oncol 2018;5:HEP05. DOI PubMed PMC

24. Spolitu S, Okamoto H, Dai W, et al. Hepatic Glucagon Signaling Regulates PCSK9 and Low-Density Lipoprotein Cholesterol. Circ Res 2019;124:38-51. DOI PubMed PMC

25. Sakata H, Rubin JS, Taylor WG, Miki T. A Rho-specific exchange factor Ect2 is induced from $\mathrm{S}$ to M phases in regenerating mouse liver. Hepatology 2000;32:193-9. DOI PubMed

26. Bang BR, Han KH, Seo GY, Croft M, Kang YJ. The protein tyrosine kinase SYK regulates the alternative p38 activation in liver during acute liver inflammation. Sci Rep 2019;9:17838. DOI PubMed PMC

27. Welch HC. Regulation and function of P-Rex family Rac-GEFs. Small GTPases 2015;6:49-70. DOI PubMed PMC

28. Harnois T, Constantin B, Rioux A, Grenioux E, Kitzis A, Bourmeyster N. Differential interaction and activation of Rho family GTPases by p210bcr-abl and p190bcr-abl. Oncogene 2003;22:6445-54. DOI PubMed

29. Bodemann BO, White MA. Ral GTPases and cancer: linchpin support of the tumorigenic platform. Nat Rev Cancer 2008;8:133-40. DOI PubMed

30. Cook DR, Rossman KL, Der CJ. Rho guanine nucleotide exchange factors: regulators of Rho GTPase activity in development and disease. Oncogene 2014;33:4021-35. DOI PubMed PMC

31. Gotoh T, Hattori S, Nakamura S, et al. Identification of Rap1 as a target for the Crk SH3 domain-binding guanine nucleotidereleasing factor C3G. Mol Cell Biol 1995;15:6746-53. DOI PubMed PMC 
32. Gotoh T, Niino Y, Tokuda M, et al. Activation of R-Ras by Ras-Guanine Nucleotide-releasing Factor*. J Cancer Res Clin Oncol 1997;272:18602-7. DOI PubMed

33. Guerrero C, Martín-Encabo S, Fernández-Medarde A, Santos E. C3G-mediated suppression of oncogene-induced focus formation in fibroblasts involves inhibition of ERK activation, cyclin A expression and alterations of anchorage-independent growth. Oncogene 2004;23:4885-93. DOI PubMed

34. Gutiérrez-Uzquiza A, Arechederra M, Molina I, et al. C3G down-regulates p38 MAPK activity in response to stress by Rap-1 independent mechanisms: involvement in cell death. Cell Signal 2010;22:533-42. DOI PubMed

35. Shakyawar DK, Dayma K, Ramadhas A, Varalakshmi C, Radha V. C3G shows regulated nucleocytoplasmic exchange and represses histone modifications associated with euchromatin. Mol Biol Cell 2017;28:984-95. DOI PubMed PMC

36. Shakyawar DK, Muralikrishna B, Radha V. C3G dynamically associates with nuclear speckles and regulates mRNA splicing. Mol Biol Cell 2018;29:1111-24. DOI PubMed PMC

37. Radha V, Mitra A, Dayma K, Sasikumar K. Signalling to actin: role of C3G, a multitasking guanine-nucleotide-exchange factor. Biosci Rep 2011;31:231-44. DOI PubMed

38. Ohba Y, Ikuta K, Ogura A, et al. Requirement for C3G-dependent Rap1 activation for cell adhesion and embryogenesis. EMBO J 2001;20:3333-41. DOI PubMed PMC

39. Ortiz-Rivero S, Baquero C, Hernandez-Cano L, et al. C3G, through its GEF activity, induces megakaryocytic differentiation and proplatelet formation. Cell Commun Signal 2018;16:101. DOI PubMed PMC

40. Guerrero C, Fernandez-Medarde A, Rojas JM, Font de Mora J, Esteban LM, Santos E. Transformation suppressor activity of C3G is independent of its CDC25-homology domain. Oncogene 1998;16:613-24. DOI PubMed

41. Okino K, Nagai H, Nakayama H, et al. Inactivation of Crk SH3 domain-binding guanine nucleotide-releasing factor $(\mathrm{C} 3 \mathrm{G})$ in cervical squamous cell carcinoma. Int J Gynecol Cancer 2006;16:763-71. DOI PubMed

42. Priego N, Arechederra M, Sequera C, et al. C3G knock-down enhances migration and invasion by increasing Rap1-mediated p38alpha activation, while it impairs tumor growth through p38alpha-independent mechanisms. Oncotarget 2016;7:45060-78. DOI PubMed PMC

43. Dayma K, Radha V. Cytoskeletal remodeling by $\mathrm{C} 3 \mathrm{G}$ to induce neurite-like extensions and inhibit motility in highly invasive breast carcinoma cells. Biochim Biophys Acta 2011;1813:456-65. DOI PubMed

44. Hirata T, Nagai H, Koizumi K, et al. Amplification, up-regulation and over-expression of C3G (CRK SH3 domain-binding guanine nucleotide-releasing factor) in non-small cell lung cancers. J Hum Genet 2004;49:290-5. DOI PubMed

45. Gutierrez-Berzal J, Castellano E, Martin-Encabo S, et al. Characterization of p87C3G, a novel, truncated C3G isoform that is overexpressed in chronic myeloid leukemia and interacts with Bcr-Abl. Exp Cell Res 2006;312:938-48. DOI PubMed

46. Sequera C, Bragado P, Manzano S, et al. C3G Is Upregulated in Hepatocarcinoma, Contributing to Tumor Growth and Progression and to HGF/MET Pathway Activation. Cancers (Basel) 2020;12:2282. DOI PubMed PMC

47. Lin Y, Mettling C, Chou C. Rap1-suppressed tumorigenesis is concomitant with the interference in ras effector signaling. FEBS Lett 2000;467:184-8. DOI PubMed

48. Sheng Y, Ding S, Chen K, et al. Functional analysis of miR-101-3p and Rap1b involved in hepatitis B virus-related hepatocellular carcinoma pathogenesis. Biochem Cell Biol 2014;92:152-62. DOI PubMed

49. Zhang L, Duan HB, Yang YS. Knockdown of Rap2B Inhibits the Proliferation and Invasion in Hepatocellular Carcinoma Cells. Oncol Res 2017;25:19-27. DOI PubMed PMC

50. Tang Z, Peng H, Chen J, et al. Raplb enhances the invasion and migration of hepatocellular carcinoma cells by up-regulating Twist 1 . Exp Cell Res 2018;367:56-64. DOI PubMed

51. Schippers M, Beljaars L, Post E, et al. Upregulation of Epac-1 in Hepatic Stellate Cells by Prostaglandin E(2) in Liver Fibrosis Is Associated with Reduced Fibrogenesis. J Pharmacol Exp Ther 2017;363:126-35. DOI PubMed

52. Zhang X, Zhuang H, Han F, et al. Sp1-regulated transcription of RasGRP1 promotes hepatocellular carcinoma (HCC) proliferation. Liver Int 2018;38:2006-17. DOI PubMed

53. Wang XK, Liao XW, Yang CK, et al. Oncogene PLCE1 may be a diagnostic biomarker and prognostic biomarker by influencing cell cycle, proliferation, migration, and invasion ability in hepatocellular carcinoma cell lines. J Cell Physiol 2020;235:7003-17. DOI PubMed

54. Kang X, Bai L, Qi X, Wang J. Screening and identification of key genes between liver hepatocellular carcinoma (LIHC) and cholangiocarcinoma (CHOL) by bioinformatic analysis. Medicine (Baltimore) 2020;99:e23563. DOI PubMed PMC

55. Shirasaki T, Honda M, Shimakami T, et al. MicroRNA-27a regulates lipid metabolism and inhibits hepatitis $\mathrm{C}$ virus replication in human hepatoma cells. $J$ Virol 2013;87:5270-86. DOI PubMed PMC

56. Calvisi DF, Ladu S, Conner EA, et al. Inactivation of Ras GTPase-activating proteins promotes unrestrained activity of wild-type Ras in human liver cancer. J Hepatol 2011;54:311-9. DOI PubMed PMC

57. Birge RB, Kalodimos C, Inagaki F, Tanaka S. Crk and CrkL adaptor proteins: networks for physiological and pathological signaling. Cell Communication and Signaling 2009;7:13. DOI PubMed PMC

58. Rodrigues SP, Fathers KE, Chan G, et al. CrkI and CrkII function as key signaling integrators for migration and invasion of cancer cells. Mol Cancer Res 2005;3:183-94. DOI PubMed

59. Guo C, Liu S, Sun MZ. The role of CT10 regulation of kinase-like in cancer. Future Oncol 2014;10:2687-97. DOI PubMed

60. Srinivasan S, Godin B. Increased Soluble CrkL in Serum of Breast Cancer Patients Is Associated with Advanced Disease. Cancers (Basel) 2019:11. DOI PubMed PMC

61. Liu CH, Chen TC, Chau GY, et al. Analysis of protein-protein interactions in cross-talk pathways reveals CRKL protein as a novel 
prognostic marker in hepatocellular carcinoma. Mol Cell Proteomics 2013;12:1335-49. DOI PubMed PMC

62. Guo C, Zhao D, Zhang Q, Liu S, Sun M-Z. miR-429 suppresses tumor migration and invasion by targeting CRKL in hepatocellular carcinoma via inhibiting Raf/MEK/ERK pathway and epithelial-mesenchymal transition. Scientific Reports 2018;8:2375. DOI PubMed PMC

63. Ren Y, Shang J, Li J, et al. The long noncoding RNA PCAT-1 links the microRNA miR-215 to oncogene CRKL-mediated signaling in hepatocellular carcinoma. J Biol Chem 2017;292:17939-49. DOI PubMed PMC

64. Guo C, Gao C, Zhao D, et al. A novel ETV6-miR-429-CRKL regulatory circuitry contributes to aggressiveness of hepatocellular carcinoma. J Exp Clin Cancer Res 2020;39:70. DOI PubMed PMC

65. Abdul S, Majid A, Wang J, Liu Q, Sun MZ, Liu S. Bidirectional interaction of lncRNA AFAP1-AS1 and CRKL accelerates the proliferative and metastatic abilities of hepatocarcinoma cells. $J$ Adv Res 2020;24:121-30. DOI PubMed PMC

66. Lin Q, Sun MZ, Guo C, Shi J, Chen X, Liu S. CRKL overexpression suppresses in vitro proliferation, invasion and migration of murine hepatocarcinoma Hca-P cells. Biomed Pharmacother 2015;69:11-7. DOI PubMed

67. Zhou Z, Sun X, Guo C, Sun M-Z, Liu S. CRKII overexpression promotes the in vitro proliferation, migration and invasion potential of murine hepatocarcinoma Hca-P cells. Oncology letters 2019;17:5169-74. DOI PubMed PMC

68. Sun X, Liu S, Wang J, et al. Annexin A5 regulates hepatocarcinoma malignancy via CRKI/II-DOCK180-RAC1 integrin and MEKERK pathways. Cell Death \& Disease 2018;9:637. DOI PubMed PMC

69. Hodge RG, Ridley AJ. Regulating Rho GTPases and their regulators. Nature Reviews Molecular Cell Biology 2016;17:496-510. DOI PubMed

70. Otsuki Y, Tanaka M, Yoshii S, Kawazoe N, Nakaya K, Sugimura H. Tumor metastasis suppressor nm23H1 regulates Rac1 GTPase by interaction with Tiam1. Proc Natl Acad Sci U S A 2001;98:4385-90. DOI PubMed PMC

71. Malliri A, Collard JG. Role of Rho-family proteins in cell adhesion and cancer. Curr Opin Cell Biol 2003;15:583-9. DOI PubMed

72. Malliri A, van der Kammen RA, Clark K, van der Valk M, Michiels F, Collard JG. Mice deficient in the Rac activator Tiam1 are resistant to Ras-induced skin tumours. Nature 2002;417:867-71. DOI PubMed

73. Strumane K, Rygiel T, van der Valk M, Collard JG. Tiam1-deficiency impairs mammary tumor formation in MMTV-c-neu but not in MMTV-c-myc mice. J Cancer Res Clin Oncol 2009;135:69-80. DOI PubMed

74. Izumi D, Toden S, Ureta E, Ishimoto T, Baba H, Goel A. TIAM1 promotes chemoresistance and tumor invasiveness in colorectal cancer. Cell Death \& Disease 2019;10:267. DOI PubMed PMC

75. Ding Y, Chen B, Wang S, et al. Overexpression of Tiam1 in hepatocellular carcinomas predicts poor prognosis of HCC patients. Int $J$ Cancer 2009;124:653-8. DOI PubMed

76. Yang W, Lv S, Liu X, Liu H, Yang W, Hu F. Up-regulation of Tiam1 and Rac1 correlates with poor prognosis in hepatocellular carcinoma. Jpn J Clin Oncol 2010;40:1053-9. DOI PubMed

77. Huang J, Ye X, Guan J, et al. Tiam1 is associated with hepatocellular carcinoma metastasis. Int J Cancer 2013;132:90-100. DOI PubMed

78. Wang W, Wang Q, Huang DB, et al. Tumor-associated mesenchymal stem cells promote hepatocellular carcinoma metastasis via a DNM3OS/KDM6B/TIAM1 axis. Cancer Lett 2021;503:19-31. DOI PubMed

79. Zhang Y, Huang J, Li Q, et al. Histone methyltransferase SETDB1 promotes cells proliferation and migration by interacting withTiam1 in hepatocellular carcinoma. BMC Cancer 2018;18:539. DOI PubMed PMC

80. Chen G, Lu L, Liu C, Shan L, Yuan D. MicroRNA-377 suppresses cell proliferation and invasion by inhibiting TIAM1 expression in hepatocellular carcinoma. PLoS One 2015;10:e0117714. DOI PubMed PMC

81. Liu Y, Ding Y, Huang J, et al. MiR-141 suppresses the migration and invasion of HCC cells by targeting Tiam1. PLoS One 2014;9:e88393. DOI PubMed PMC

82. Cheng W, Liu Y, Zuo Z, et al. Biological effects of RNAi targeted inhibiting Tiam1 gene expression on cholangiocarcinoma cells. Int J Clin Exp Pathol 2015;8:15511-26. PubMed PMC

83. Chen JS, Su IJ, Leu YW, Young KC, Sun HS. Expression of T-cell lymphoma invasion and metastasis 2 (TIAM2) promotes proliferation and invasion of liver cancer. Int J Cancer 2012;130:1302-13. DOI PubMed

84. Yen WH, Ke WS, Hung JJ, Chen TM, Chen JS, Sun HS. Sp1-mediated ectopic expression of T-cell lymphoma invasion and metastasis 2 in hepatocellular carcinoma. Cancer Med 2016;5:465-77. DOI PubMed PMC

85. Tang J, Liu C, Xu B, Wang D, Ma Z, Chang X. ARHGEF10L contributes to liver tumorigenesis through RhoA-ROCK1 signaling and the epithelial-mesenchymal transition. Exp Cell Res 2019;374:46-68. DOI PubMed

86. Schmidt A, Hall A. Guanine nucleotide exchange factors for Rho GTPases: turning on the switch. Genes Dev 2002;16:1587-609. DOI PubMed

87. Gao J, Jia WD. Expression of Rho Guanine Nucleotide Exchange Factor 39 (ARHGEF39) and Its Prognostic Significance in Hepatocellular Carcinoma. Med Sci Monit 2019;25:7826-35. DOI PubMed PMC

88. Wang H, Li Y, Wang Y, Han ZG, Cai B. C9orf100, a new member of the Dbl-family guanine nucleotide exchange factors, promotes cell proliferation and migration in hepatocellular carcinoma. Mol Med Rep 2012;5:1169-74. DOI PubMed

89. Zhou J, Tao Y, Peng C, Gu P, Wang W. miR-503 regulates metastatic function through Rho guanine nucleotide exchanger factor 19 in hepatocellular carcinoma. J Surg Res 2014;188:129-36. DOI PubMed

90. Chen L, Chan TH, Yuan YF, et al. CHD1L promotes hepatocellular carcinoma progression and metastasis in mice and is associated with these processes in human patients. J Clin Invest 2010;120:1178-91. DOI PubMed PMC

91. Chen J, Xia H, Zhang X, et al. ECT2 regulates the Rho/ERK signalling axis to promote early recurrence in human hepatocellular carcinoma. J Hepatol 2015;62:1287-95. DOI PubMed 
92. Fang ZQ, Li MC, Zhang YQ, Liu XG. MiR-490-5p inhibits the metastasis of hepatocellular carcinoma by down-regulating E2F2 and ECT2. J Cell Biochem 2018;119:8317-24. DOI PubMed

93. Yu Y, Cai O, Wu P, Tan S. MiR-490-5p inhibits the stemness of hepatocellular carcinoma cells by targeting ECT2. J Cell Biochem 2019;120:967-76. DOI PubMed

94. Gao J, Dai C, Yu X, Yin XB, Zhou F. Upregulated microRNA-194 impairs stemness of cholangiocarcinoma cells through the Rho pathway via inhibition of ECT2. J Cell Biochem 2020;121:4239-50. DOI PubMed

95. Toksoz D, Williams DA. Novel human oncogene lbc detected by transfection with distinct homology regions to signal transduction products. Oncogene 1994;9:621-8. PubMed

96. Sterpetti P, Marucci L, Candelaresi C, et al. Cell proliferation and drug resistance in hepatocellular carcinoma are modulated by Rho GTPase signals. Am J Physiol Gastrointest Liver Physiol 2006;290:G624-32. DOI PubMed

97. Ahronian LG, Zhu LJ, Chen YW, Chu HC, Klimstra DS, Lewis BC. A novel KLF6-Rho GTPase axis regulates hepatocellular carcinoma cell migration and dissemination. Oncogene 2016;35:4653-62. DOI PubMed PMC

98. Wang R, Zhao N, Li S, et al. MicroRNA-195 suppresses angiogenesis and metastasis of hepatocellular carcinoma by inhibiting the expression of VEGF, VAV2, and CDC42. Hepatology 2013;58:642-53. DOI PubMed

99. Zeng Y, Guo Z, Hu Z, et al. FGD1 exhibits oncogenic properties in hepatocellular carcinoma through regulating cell morphology, autophagy and mitochondrial function. Biomed Pharmacother 2020;125:110029. DOI PubMed

100. Martínez-López N, García-Rodríguez JL, Varela-Rey M, et al. Hepatoma cells from mice deficient in glycine N-methyltransferase have increased RAS signaling and activation of liver kinase B1. Gastroenterology 2012;143:787-98.e13. DOI PubMed PMC

101. Sun X, Wang M, Zhang F, Kong X. Inhibition of NET-1 suppresses proliferation and promotes apoptosis of hepatocellular carcinoma cells by activating the PI3K/AKT signaling pathway. Exp Ther Med 2019;17:2334-40. DOI PubMed PMC

102. Molee P, Adisakwattana P, Reamtong O, et al. Up-regulation of AKAP13 and MAGT1 on cytoplasmic membrane in progressive hepatocellular carcinoma: a novel target for prognosis. Int J Clin Exp Pathol 2015;8:9796-811. PubMed PMC

103. Cheng IK, Tsang BC, Lai KP, et al. GEF-H1 over-expression in hepatocellular carcinoma promotes cell motility via activation of RhoA signalling. J Pathol 2012;228:575-85. DOI PubMed

104. Wang B, Fang J, Qu L, Cao Z, Zhou J, Deng B. Upregulated TRIO expression correlates with a malignant phenotype in human hepatocellular carcinoma. Tumour Biol 2015;36:6901-8. DOI PubMed

105. Wong CM, Lee JM, Ching YP, Jin DY, Ng IO. Genetic and epigenetic alterations of DLC-1 gene in hepatocellular carcinoma. Cancer Res 2003;63:7646-51. PubMed

106. Wong CM, Yam JW, Ching YP, et al. Rho GTPase-activating protein deleted in liver cancer suppresses cell proliferation and invasion in hepatocellular carcinoma. Cancer Res 2005;65:8861-8. DOI PubMed

107. Ching YP, Wong CM, Chan SF, et al. Deleted in liver cancer (DLC) 2 encodes a RhoGAP protein with growth suppressor function and is underexpressed in hepatocellular carcinoma. J Biol Chem 2003;278:10824-30. DOI PubMed

108. Xiaorong L, Wei W, Liyuan Q, Kaiyan Y. Underexpression of deleted in liver cancer 2 (DLC2) is associated with overexpression of RhoA and poor prognosis in hepatocellular carcinoma. BMC Cancer 2008;8:205. DOI PubMed PMC 